\title{
Management of recurrent hepatocellular carcinoma after resection
}

\author{
Hwee Leong $\operatorname{Tan}^{1}$, Brian K. P. Goh ${ }^{1,2}$ \\ ${ }^{1}$ Department of Hepatopancreatobiliary and Transplant Surgery, Singapore General Hospital, Singapore, Singapore; ${ }^{2}$ Duke-NUS Medical School \\ Singapore, Singapore, Singapore \\ Correspondence to: Dr. Brian K. P. Goh, MBBS, MMed, MSc, FRCSEd. Professor and Senior Consultant, Department of Hepatopancreatobiliary and \\ Transplant Surgery, Singapore General Hospital, 20 College Road, Academia Level 5, Singapore 169856, Singapore. Email: bsgkp@hotmail.com.
}

Submitted Feb 06, 2020. Accepted for publication Feb 24, 2020.

doi: 10.21037/hbsn.2020.03.07

View this article at: http://dx.doi.org/10.21037/hbsn.2020.03.07

\section{Introduction}

Hepatocellular carcinoma (HCC) is currently the fifth most common cancer globally, accounting for the third highest cancer-related deaths (1). Liver resection is the treatment modality of choice for resectable HCCs with adequate liver function in the absence of portal hypertension (1), but actuarial recurrence rates remain as high as $70 \%$ at 5 years post-resection (2). The recurrence of HCC post-resection portends poorer prognosis, with a $24 \%$ reduction in 5 -year survival (2). While there have been a multitude of guidelines for the management of primary HCC across the world (3), the international expert consensus recently published by Wen et al. represents the first systematic, evidence-based consensus guidelines for the management of recurrent HCC (RHCC) following liver resection (4).

\section{Unique considerations in RHCC}

There are a few key considerations in the management of RHCC which sets it apart from managing primary HCC. Firstly, the disease biology of RHCC usually represents a subset of HCC with a higher proportion of aggressive behavior, evidenced by the poorer prognosis which RHCC carries (2). Amongst RHCC, there are two described mechanisms of recurrence with distinct clinicopathologic characteristics-intrahepatic metastasis (IM) and multicentric occurrence (MO) $(5,6)$. Recurrences due to IM are thought to originate from the primary HCC, tend to be similarly or less differentiated than the primary HCC, and usually recur earlier (within one year) following resection. Recurrences due to MO occur de novo, tend to be better differentiated, and usually recur later (more than one year) following resection. A meta-analysis of seven studies comprising 704 patients examining the comparative prognosis of IM and MO RHCC concluded that MO was associated with significantly better overall ( $\mathrm{HR}=0.495$, 95\% CI: 0.378 to $0.648, \mathrm{P}<0.001)$ and disease-free survival $(\mathrm{HR}=0.774,95 \% \mathrm{CI}: 0.663$ to $0.903, \mathrm{P}=0.001)(6)$. Additionally, following repeat liver resection for RHCC, further recurrences are significantly lower for MO (7).

Secondly, the future liver remnant (FLR) is invariably smaller when contemplating resection as a treatment modality for RHCC as compared to the primary HCC. While several retrospective cohort studies have demonstrated the safety and efficacy of repeat hepatectomies for RHCC $(8,9)$, there remains inherent selection bias in examining these outcomes in patients who have been preselected to undergo repeat liver resection. The comparative proportion of patients with primary HCC and RHCC who have tumours amenable to liver resection remains unclear.

Thirdly, the underlying liver function is likely to be poorer in RHCC as compared to primary HCC. This is because liver cirrhosis is a major risk factor for $\mathrm{MO}$ of RHCC. This could also in part be due to the natural progression of the underlying chronic liver disease, as RHCC tend to occur later in terms of temporality. Additionally, a proportion of patients with RHCC may have experienced post-hepatectomy liver failure following previous liver resection, which can result in enduring impairments to underlying liver function, and has been associated with poorer long-term overall and disease-free survival $(10,11)$. 


\section{Implications of RHCC on Management}

The general management principles of RHCC as proposed by Wen et al. in their consensus guidelines largely mirror that of primary HCC, taking into account the baseline functional status, underlying liver function (Child-Pugh class), tumour characteristics (presence of extrahepatic disease, tumour number and tumour size) and treatmentspecific considerations (e.g., FLR for liver resection, proximity to major biliovascular structures for locoregional interventions) $(1,4)$.

The various treatment modalities for HCC including liver resection, liver transplantation and locoregional interventions [e.g., transarterial chemoembolization (TACE), radiofrequency ablation (RFA)] apply similarly to RHCC. Repeat liver resection for RHCC remains a widely adopted treatment option especially in the East for resectable lesions with adequate underlying liver function, and has been reported to achieve long-term survival benefit $(8,9)$, superior to TACE (12). Salvage liver transplantation is the treatment of choice when treating RHCC especially following prior liver resection. It offers long-term survival benefit comparable to primary liver transplantation $(13,14)$. Additionally, when compared to repeated liver resection and locoregional treatments for RHCC, it offers superior long-term outcomes $(15,16)$. The main limitation to the wider use of liver transplant for recurrent HCC is organ scarcity. This is reflected in its role as an alternative treatment option for Child-Pugh class A and B patients, and as the only curative option for Child-Pugh class C patients in the consensus guidelines by Wen et al. (4). However, it is important to emphasize than in most instances, salvage liver transplant would likely provide the best long-term prognosis for patients with early-stage RHCC. Hence, this option should always be made known to the patient including the possibility of living donor transplantation.

In terms of locoregional interventions, RFA has been well-established as a curative option for individual early HCC lesions less than $2-3 \mathrm{~cm}$ in size, in both the primary and RHCC settings, while TACE is primarily used as bridging and/or palliative treatment of larger lesions not amenable to curative options $(1,4)$. Additionally, combination therapy of RFA and TACE has been shown to be superior to either modality used in isolation when treating RHCC (17).

In recognition of the important role disease biology plays in treatment outcomes, Wen et al. highlighted the presence of 'recurrent high risks' as a dichotomizing tool to recommend upfront liver resection as opposed to locoregional interventions for RHCC (4). In the presence of high-risk features, which includes a short interval (less than 1 year) between primary resection and RHCC, the guidelines recommend upfront locoregional interventions as a therapeutic trial, with patients who respond favorably then considered for repeat liver resection. This approach helps patients with poor disease biology who progress on locoregional interventions avoid the morbidity of a repeat resection which may not have yielded them significant long-term survival benefit $(5-7,18)$. It is also important to emphasize that although consideration for the use of adjuvant treatment to reduce recurrence in high risk patients after liver resection was proposed in the guidelines, there is lack of robust evidence in the literature supporting this recommendation and it is not known to date if the use of adjuvant treatment would improve patient survival.

\section{Future directions}

While the treatment principles of RHCC largely mirrors that of primary HCC, the poorer disease biology and morbidity associated with repeated interventions necessitate a prudent approach towards managing RHCC. More data is needed to establish robust prediction models for outcomes following various treatment options for RHCC, so as to improve patient selection when contemplating surgical options, and to improve organ allocation when contemplating salvage liver transplantation.

Additionally, anatomical alterations in RHCC as a result of post-operative adhesions and post-resection liver hypertrophy can potentially complicate repeat liver resection, especially when minimally invasive approaches are adopted. Existing literature on the comparative outcomes of open versus laparoscopic repeat liver resection for RHCC suggest comparable perioperative outcomes, with mixed data on differences in operative time and longterm survival outcomes $(19,20)$. Extrapolating from the findings of the first randomized controlled trial comparing laparoscopic and open liver resection, the laparoscopic approach potentially offers a lower postoperative morbidity profile (21). Whether this applies to in the treatment of RHCC remains to be confirmed by a prospective trial.

\section{Acknowledgments}

Funding: None. 


\section{Footnote}

Provenance and Peer Review: This article was commissioned by the editorial office of Hepatobiliary Surgery and Nutrition. The article did not undergo external peer review.

Conflicts of Interest: Both authors have completed the ICMJE uniform disclosure form (available at http://dx.doi. org/10.21037/hbsn.2020.03.07). The authors have no conflicts of interest to declare.

Ethical Statement: The authors are accountable for all aspects of the work in ensuring that questions related to the accuracy or integrity of any part of the work are appropriately investigated and resolved.

Open Access Statement: This is an Open Access article distributed in accordance with the Creative Commons Attribution-NonCommercial-NoDerivs 4.0 International License (CC BY-NC-ND 4.0), which permits the noncommercial replication and distribution of the article with the strict proviso that no changes or edits are made and the original work is properly cited (including links to both the formal publication through the relevant DOI and the license). See: https://creativecommons.org/licenses/by-nc-nd/4.0/.

\section{References}

1. Marrero JA, Kulik LM, Sirlin CB, et al. Diagnosis, Staging and Management of Hepatocellular Carcinoma: 2018 Practice Guidelines by the American Association for the Study of Liver Diseases. Hepatology 2018;68:723-50.

2. Tabrizian P, Jibara G, Shrager B, et al. Recurrence of hepatocellular cancer after resection: patterns, treatments, and prognosis. Ann Surg 2015;261:947-55.

3. Song P, Tobe RG, Inagaki $\mathrm{Y}$, et al. The management of hepatocellular carcinoma around the world: a comparison of guidelines from 2001 to 2011. Liver Int 2012;32:1053-63.

4. Wen T, Jin C, Facciorusso A, et al. Multidisciplinary management of recurrent and metastatic hepatocellular carcinoma after resection: an international expert consensus. Hepatobiliary Surg Nutr 2018;7:353-71.

5. Hao S, Fan P, Chen S, et al. Distinct Recurrence Risk Factors for Intrahepatic Metastasis and Multicenter Occurrence After Surgery in Patients with Hepatocellular Carcinoma. J Gastrointest Surg 2017;21:312-20.

6. Yang SL, Luo YY, Chen M, et al. A systematic review and meta-analysis comparing the prognosis of multicentric occurrence and vs. intrahepatic metastasis in patients with recurrent hepatocellular carcinoma after hepatectomy. HPB (Oxford) 2017;19:835-42.

7. Huang ZY, Liang BY, Xiong M, et al. Long-term outcomes of repeat hepatic resection in patients with recurrent hepatocellular carcinoma and analysis of recurrent types and their prognosis: a single-center experience in China. Ann Surg Oncol 2012;19:2515-25.

8. Chan DL, Morris DL, Chua TC. Clinical efficacy and predictors of outcomes of repeat hepatectomy for recurrent hepatocellular carcinoma - a systematic review. Surg Oncol 2013;22:e23-30.

9. Zhou Y, Sui C, Li B, et al. Repeat hepatectomy for recurrent hepatocellular carcinoma: a local experience and a systematic review. World J Surg Oncol 2010;8:55.

10. Rahbari NN, Garden OJ, Padbury R, et al. Posthepatectomy liver failure: a definition and grading by the International Study Group of Liver Surgery (ISGLS). Surgery 2011;149:713-24.

11. Fukushima K, Fukumoto T, Kuramitsu K, et al. Assessment of ISGLS definition of posthepatectomy liver failure and its effect on outcomes in patients with hepatocellular carcinoma. J Gastrointest Surg 2014;18:729-36.

12. Wang DY, Liu L, Qi XS, et al. Hepatic Re-resection Versus Transarterial Chemoembolization for the Treatment of Recurrent Hepatocellular Carcinoma after Initial Resection: a Systematic Review and Meta-analysis. Asian Pac J Cancer Prev 2015;16:5573-8.

13. Guo Y, Tan EK, Krishnamoorthy TL, et al. Outcomes of salvage liver transplant for recurrent hepatocellular carcinoma: A comparison with primary liver transplant. Ann Hepatobiliary Pancreat Surg 2019;23:1-7.

14. Hu Z, Wang W, Li Z, et al. Recipient outcomes of salvage liver transplantation versus primary liver transplantation: a systematic review and meta-analysis. Liver Transpl 2012;18:1316-23.

15. Lim C, Shinkawa H, Hasegawa K, et al. Salvage liver transplantation or repeat hepatectomy for recurrent hepatocellular carcinoma: An intent-to-treat analysis. Liver Transpl 2017;23:1553-63.

16. Wang HL, Mo DC, Zhong JH, et al. Systematic review of treatment strategy for recurrent hepatocellular carcinoma Salvage liver transplantation or curative locoregional therapy. Medicine (Baltimore) 2019;98:e14498.

17. Song Q, Ren W, Fan L, et al. Long-Term Outcomes of Transarterial Chemoembolization Combined 
with Radiofrequency Ablation Versus Transarterical Chemoembolization Alone for Recurrent Hepatocellular Carcinoma After Surgical Resection. Dig Dis Sci 2020;65:1266-75.

18. Guo Y, Chua DW, Koh YX, et al. Preoperative Predictors Including the Role of Inflammatory Indices in Predicting Early Recurrence After Re-resection for Recurrent Hepatocellular Carcinoma. World J Surg 2019;43:2587-94.

19. Liu K, Chen $Y, W u X$, et al. Laparoscopic liver reresection is feasible for patients with posthepatectomy

Cite this article as: Tan HL, Goh BKP. Management of recurrent hepatocellular carcinoma after resection. Hepatobiliary Surg Nutr 2020;9(6):780-783. doi: 10.21037/ hbsn.2020.03.07 hepatocellular carcinoma recurrence: a propensity score matching study. Surg Endosc 2017;31:4790-8.

20. Goh BKP, Syn N, Teo JY, Perioperative Outcomes of Laparoscopic Repeat Liver Resection for Recurrent HCC: Comparison with Open Repeat Liver Resection for Recurrent HCC and Laparoscopic Resection for Primary HCC. World J Surg 2019;43:878-85.

21. Fretland ÅA, Dagenborg VJ, Bjørnelv GMW, et al. Laparoscopic Versus Open Resection for Colorectal Liver Metastases: The OSLO-COMET Randomized Controlled Trial. Ann Surg 2018;267:199-207. 